\title{
Ping-Pong Fracture in Newborn: A Rare Diagnosis
}

\section{Fratura em Pingue-Pongue no Recém-Nascido: Um Diagnóstico Raro}

Joana Brandão SILVA $\triangle^{1}$, Anabela JOÃO ${ }^{2}$, Nise MIRANDA ${ }^{2}$

Acta Med Port 2019 Jul-Aug;32(7-8):549-549 - https://doi.org/10.20344/amp.10726

Keywords: Fractures, Spontaneous; Infant, Newborn; Parietal Bone/injuries; Skull Fracture, Depressed/diagnostic imaging

Palavras-chave: Fratura do Crânio com Afundamento/diagnóstico por imagem; Fraturas Espontâneas; Osso Parietal/lesões; RecémNascido

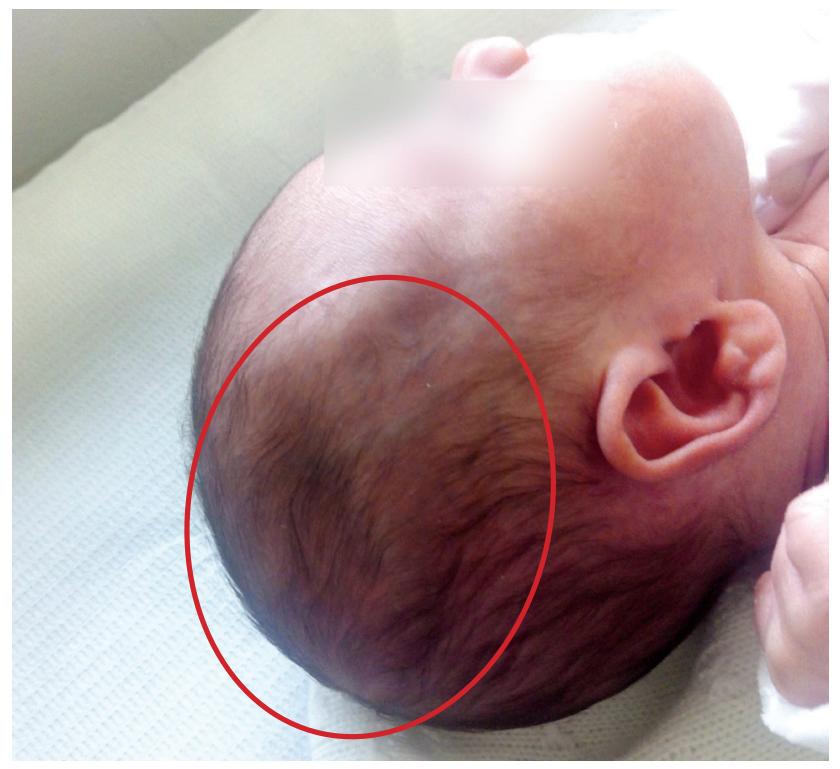

Figure 1 - Newborn of 13 days with right parietal depression present since birth

A neonate from the first pregnancy of a healthy 36-yearold woman was born by eutocic delivery with birthweight $2620 \mathrm{~g}$. There was no trauma during pregnancy or labor. She presented a depression in the right parietal region, approximately $4 \times 3 \mathrm{~cm}$ and a depth of $2 \mathrm{~cm}$ (Fig.1); the remaining physical examination was normal. Our diagnostic hypothesis was ping-pong fracture. Skull radiograph revealed an abnormal concavity in the parietal bone. Cranial ultrasound showed no intracerebral bleeds or haematomas (Fig. 2). Watchful waiting was decided, and within three months there was spontaneous elevation of the deformity.

Ping pong fractures in neonates occur in $4-10 / 100000$ live births, and are due to the relatively malleable nature of

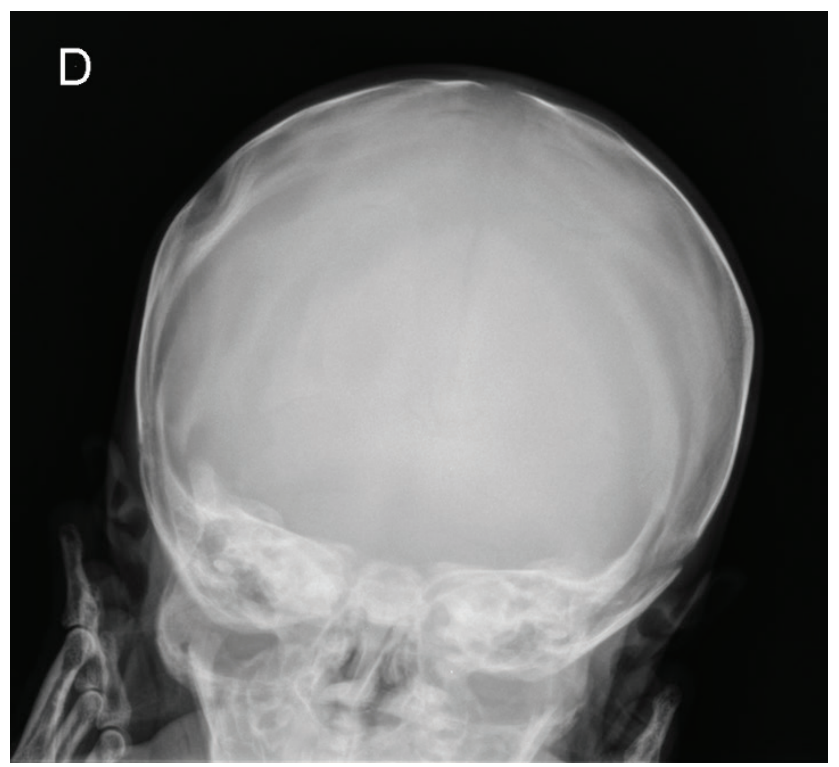

Figure 2 - Right parietal depression visualized in the plain radiograph of the skull, with no associated fracture line

the skull. ${ }^{1,2}$ The main cause of these fractures is birth trauma (instrumentation or maternal bone structures), causing inward buckling of the bones. ${ }^{1,3}$ Skull radiography shows the degree of deformation and cranial ultrasound can identify intracranial hemorrhages or hematomas. Although computed tomography scan is more sensitive, it should be performed only if there is diagnostic doubt or complications. ${ }^{1}$ Treatment options include non-surgical reduction using digital pressure or vacuum extractor, surgical elevation or watchful waiting. ${ }^{3,4}$ The choice is based on clinical examination, the severity of the fracture and underlying brain injury. ${ }^{1}$ The prognosis is good in spontaneous cases and when neurological examination is normal. ${ }^{3,4}$

PROTECTION OF HUMANS AND ANIMALS: The authors declare that the procedures were followed according to the regulations established by the Clinical Research and Ethics Committee and to the Helsinki Declaration of the World Medical Association.

DATA CONFIDENTIALITY: The authors declare having followed the protocols in use at their working center regarding patients' data publication.

PATIENT CONSENT: Obtained.

CONFLICTS OF INTEREST: All authors report no conflict of interest.

FUNDING SOURCES: This research received no specific grant from any funding agency in the public, commercial, or not-for-profit sectors.

\section{REFERENCES}

1. Preston D, Jackson S, Gandhi S. Non-traumatic depressed skull fracture in a neonate or "ping pong" fracture. BMJ Case Rep. 2015;2015.

2. Brittain C, Muthukumar P, Job S, Sank S. 'Ping pong' fracture in a term infant. BMJ Case Rep. 2012;2012.

3. Sorar M, Fesli R, Gürer B, Kertmen H, Sekerci Z. Spontaneous elevation of a ping-pong fracture: Case report and review of the literature. Pediatr Neurosurg. 2013;48:324-6.

4. Loire M, Barat M, Mangyanda Kinkembo L, Lenhardt F, M'buila C. Spontaneous ping-pong parietal fracture in a newborn. Arch Dis Child Fetal Neonatal Ed. 2017; 102:F160-1.

1. Paediatric Department. Vila Nova de Gaia/Espinho Hospital Centre. Vila Nova de Gaia. Portugal.

2. Neonatology Division. Paediatric Department. Vila Nova de Gaia/Espinho Hospital Centre. Vila Nova de Gaia. Portugal.

$\triangle$ Autor correspondente: Joana Raquel Brandão da Silva. joanarbsilva0@gmail.com

Recebido: 26 de abril de 2018 - Aceite: 03 de dezembro de 2018 | Copyright @ Ordem dos Médicos 2019 